\title{
A UNIDADE DO PODER EM MARSÍLIO DE PÁDUA
}

\section{THE UNITY OF POWER ACCORDING TO MARSILIUS OF PADUA}

\author{
Sérgio Ricardo Strefling*
}

\begin{abstract}
RESUMO - Marsílio de Pádua foi um pensador da Idade Média que escreveu duas obras de filosofia política que influenciaram a modernidade. Este estudo analisa o capítulo 17 da primeira parte do Defensor Pacis, onde se trata da unidade do governo ou do principado. Se houver muitos em número ou espécie, tal como acontece nas grandes cidades e, em particular, em um reino, aí deve haver então um supremo governante, a quem os demais estejam subordinados e por quem sejam dirigidos. Trata-se de uma unidade de ordem, não de uma unidade absoluta, ou seja, de muitos homens considerados ou de um conjunto de pessoas, que se afirma constituir algo único quantitativamente.
\end{abstract}

PALAVRAS-CHAVE - Marsílio de Pádua. Filosofia política medieval. Poder. Governo. Unidade.

ABSTRACT - Marsilius of Padua was a philosopher of the Middle Ages who wrote two books of political philosophy that have had influence on modernity. This study makes an analysis of chapter 17 of Defensor Pacis, where the subject is the unity of government. If there are several beings, in number or in species, as it seems to be the case in great towns, and in particular in a kingdom, then there should be among them one in number that stays aboven them all, to whom all others are subordinated and by whom all are directed. This a unity of order, not a unity simply speaking but rather a plurality of human beings that is affirmed to constitute one thing in number.

KEYWORDS - Marsilius of Padua. Medieval political philosophy. Power. Government. Unity.

* Universidade Federal de Pelotas.

\begin{tabular}{|l|l|l|l|l|l|}
\hline Veritas & Porto Alegre & v. 56 & n. 2 & maio/ago. 2011 & p. 165-177 \\
\hline
\end{tabular}


Marsílio Mainardini (1280-1342), médico e filósofo paduano, ao tratar da sociedade humana, embora se inspire parcialmente em Aristóteles ${ }^{1}$ e aceite a antropologia agostiniana ${ }^{2}$, apresenta, no entanto, na sua obra Defensor Pacis ${ }^{3}$ (1324), a civitas não como o resultado de um processo natural, conforme o Estagirita, nem fundamenta a mesma no direito divino, mas entende que essa se origina da experiência humana e do exercício da razão. Este estudo analisa o capítulo 17 da dictio prima do Defensor Pacis. Dialogando com estudiosos do tema em questão, apresenta-se a tese do paduano, ou seja, a necessidade da indivisibilidade ou unidade do governo. Para tal, apresentaremos, inicialmente, algumas características da civitas na concepção de Marsílio.

Os oito primeiros capítulos da obra do paduano são dedicados à análise e compreensão da civitas. Essa, que hoje traduziríamos por "sociedade civil" ou "Estado", deve ser organizada racionalmente. Afirma o filósofo que, conforme as comunidades foram crescendo, a experiência dos homens foi aumentando, assim como as habilidades, as regras ou maneiras de viver foram sendo consolidadas, de forma que os diversos grupos sociais, existentes na cidade, passaram a ser mais claramente distintos uns dos outros. Enfim, a razão e a experiência humanas, gradualmente, foram descobrindo o que é necessário para viver, e viver bem, a fim de poderem realizar-se ${ }^{4}$.

1 Cf. DP I, 4,3: "De vivere autem et bene vivere seu bona vita secundum primum modum, mundanum scilicet, ac de hiis, que propter ipsum necessaria sunt, comprehenderunt per demonstracionem philosophi gloriosi rem quasi completam. Unde propter ipsum consequendum concluserunt ipsi necessitatem civilis communitatis, sine qua vivere hoc sufficiens obtineri non potest. Quorum eciam eximius Aristoteles 1 sue Politice cap. 1 dixit: Omnes (homines) ferri ad ipsam, et secundum nature impetum propter hoc".

2 Cf. DP I, 6,1-2: "Et propterea oportet attendere, quod licet primus homo, Adam videlicet, creatus fuerit principaliter propter Dei gloriam, sicuti cetere creature, fuit ipse tamen creatus singulariter ab aliis speciebus corruptibilium, quoniam ad imaginem Dei et similitudinem, ut capax et particeps esset felicitatis eterne post vitam presentis seculi (...). Verum quia suam corrupit innocenciam seu originalem iusticiam et graciam in esu prohibiti sibi ligni, divinum in hoc transgrediendo mandatum, repente lapsus est in culpam atque miseriam sive penam, penam inquam, privacionis felicitatis eterne, ad quam Dei gloriosi beneficio cum sua posteritate qualibet finaliter fuerat ordinatus".

3 Utilizaremos a versão em língua portuguesa de José Antônio C. R. de Souza, a saber, O Defensor da Paz, Petrópolis, Vozes, 1997. A edição latina citada será de Richard Scholz, Fontes Iuris Germanici Antiqui ex Monumenta Germaniae Historica, Hannover, Hahnsche Buchhandlung, 1932.

4 Cf. DP I,3,5: "Augmentatis autem hiis successive, aucta est hominum experiencia, invente sunt artes et regule ac modi vivendi perfecciores, distincte quoque amplius communitatum partes. Demum vero que necessaria sunt ad vivere et bene vivere, per hominum racionem et experienciam perducta sunt ad complementum, et instituta est perfecta communitas vocata civitas cum suarum parcium distinccione, cuius continuo determinacionem aggrediemur". 
A civitas deve compor-se de determinadas partes, se for previamente bem planejada, para que possa estar racionalmente organizada. Entre as partes que compõem o Estado, o médico paduano salienta a pars principans, ou seja, o governo. Trata-se de algo indispensável, análogo ao coração de um organismo vivo. Esse grupo é conditio sine qua non para a civitas existir e cumprir a sua finalidade, qual seja, a realização da vita sufficiens. Os diversos grupos ${ }^{5}$ que formam a comunidade civil podem, em determinado tempo, ser dispensáveis, porém, jamais a parte governante poderá estar ausente. Essa, inicialmente formada, é o coração ou algo análogo ao mesmo; conforme Aristóteles, essa parte é mais nobre e mais perfeita em suas qualidades do que as demais de um organismo vivo. A natureza, ao gerá-la, nela estabeleceu uma força e um instrumento pelos quais as outras partes são formadas, a partir da matéria que lhes convém. Por isso mesmos, estão separadas, diferenciadas e ordenadas umas às outras, conservam-se em suas propriedades e preservam-se de qualquer dano. Ainda, quando as outras partes se enfraquecem, por causa de certas doenças ou devido a outro obstáculo, são curadas em virtude da potência do coração. O governo ou o principado é esse órgão vital, cuja virtude universal em sua causalidade é a lei, e cujo poder ativo é a autoridade de julgar, mandar e executar as sentenças relativas ao útil e justo civil. A suficiência que se têm pelas outras partes ou ofícios da cidade, se faltar, poder-se-ia, por outro caminho, suprir de um modo suficiente, ainda que isso não fosse fácil. Mas, faltando o governo, a comunidade civil não pode manter-se, pois, conforme afirma o Evangelho, é inevitável que haja escândalos, e só o governo poderá coibir os abusos.

Inicialmente, o nosso autor, ao tratar da necessidade da unidade numérica do supremo governo da cidade, ou do reino, afirma que em uma só cidade ou em um único reino deve haver apenas um principado. Se houver muitos poderes em número e espécie, como parece ser conveniente nas grandes cidades, nesse caso, deverá haver

5 Cf. DP I, 5, 1: "Dicamus quod partes seu officia civitatis sunt sex generum, ut dixit Aristoteles 7 Politice, capitulo 6: agricultura, artificium, militaris, pecuniativa, sacerdocium et iudicialis seu consiliativa".

6 Cf. DP I, 15, 6: "Hiis autem proporcionaliter contemplandum in civitate convenienter instituta secundum racionem. Nam ab anima universitatis civium aut eius valencioris partis formatur aut formari debet in ea pars una primum proporcionata cordi, in qua siquidem virtutem quandam seu formam statuit cum activa potencia seu auctoritate instituendi partes reliquas civitatis. Hec autem pars est principatus, cuius quidem virtus causalitate universalis lex est, et cuius activa potencia est auctoritas iudicandi, precipiendi et exequendi sentencias conferencium et iustorum civilium, propter quod dixit Aristoteles 7 Politice, cap. 6, partem hanc esse omnium aliarum necessariissimam in civitate". 
um poder supremo ou único, pelo qual os demais estejam regulados e subordinados, e os erros desses sejam corrigidos por esse supremo poder ${ }^{7}$.

Quillet demonstra que a unidade do governo era um princípio defendido por muitos autores daquele tempo. Tomás de Aquino, no De monarchia, defende a necessidade da unidade para a paz, e na Summa contra gentiles declara que o melhor regime para a multidão é aquele onde um só governa, porque é mais oportuno que seja uma a causa da unidade do que muitas. Dante, no De monarchia, defende a unidade do gênero humano, ao estabelecer analogia com a unidade de Deus. João Quidort, no De potestate regia et papali, defende a tese da maior força da virtus, se essa pertence a uma só pessoa, bem como a impossibilidade de ser rei, se esse não mandar sozinho. Egídio Romano, no De regimine principum, assinala a unidade do governo como requisito para a paz, a vantagem de que a virtude se concentre em um só homem, a analogia com a unidade que rege os organismos naturais e o bem comum como fim. Ockham não acredita que um povo esteja bem governado, se não estiver submetido ao governo de $\mathrm{um}^{8}$. Todos esses autores mostram a sua preferência por um poder unipessoal, ou seja, pela monarquia. Marsílio, ao contrário, entende a unidade de governo como unidade na função, e não que seja necessário um governo unipessoal. O filósofo de Pádua, ainda que prefira a monarquia, admite que o governo seja unitário e, contudo, exercido por um conselho mais ou menos amplo, como acontece na aristocracia ou na constituição republicana. Nesse caso, a ação do governo é coletiva, mas não múltipla e unitária, enquanto tomada de decisão. O essencial é que o governo seja composto por um só homem ou por muitos, mantenha a unidade de ofício ou unidade de ação.

Reiteramos que não só este supremo principado necessariamente há de ser uno, não múltiplo, caso a cidade ou o reino estejam bem organizados, mas também o próprio governante, não enquanto considerado quantitativa e pessoalmente, mas de modo particular no que se refere à atividade governamental, pois existe um governo supremo, único em quantidade, bem temperado, em que muitas pessoas governam como se fossem uma somente, por exemplo a

7 Cf. DP I, 17, 1: "Hiis autem habitum erit dicere de principantis seu principatus unitate; ad quam siquidem ingredientes, dicamus: quod in civitate unica seu regno unico esse oportet unicum tantummodo principatum, aut sit plures numero vel specie, sicut in magnis civitatibus expedire videtur et máxime in regno sumpto secundum primam significacionem, oportet inter ipsos unicum numero esse supremum omnium, ad quem et per quem reliqui reducantur et regulentur, et contingentes in ipsis errores per ipsum eciam corrigantur".

8 Cf. J. Quillet, Le Défenseur de la Paix, Paris, Vrin, 1960, p. 155-156. 
aristocracia e a república. [...] No entanto, essas várias pessoas se constituem quantitativamente num único governo quanto à atividade governamental, por causa da unidade em toda ação que realizam, em todo julgamento, preceito ou sentença que proferem. Conforme as leis estabelecidas sobre isto, todos aqueles atos só podem ser efetivamente executados de comum acordo e com o assentimento dos que governam ou de sua parte preponderante, de forma alguma apenas por um único indivíduo. Tendo em vista, pois, a unidade quantitativa da ação realizada por aquelas pessoas é que se considera tal governo como unitário, pouco importa se exercido por um ou vários indivíduos. Todavia, essa mesma unidade não é requerida para os demais ofícios ou grupos sociais existentes na cidade, pois as muitas pessoas pertencentes a cada um deles, embora façam parte da cidade, podem e devem agir separadamente realizando tarefas semelhantes ou distintas em espécie. Tal unidade de ação nos outros ofícios existentes na cidade seria intolerável e prejudicial não apenas a toda comunidade mas ainda a cada um de seus membros. ${ }^{9}$

Segundo Skinner, Marsílio é um implacável inimigo da pluralidade de estruturas ou instituições e considera o seu pensamento incompatível com a distribuição descentralizada de poderes tipicamente medieval ${ }^{10}$. O paduano admite que nas cidades extensas, em territórios com grande população, como os reinos, são necessárias várias instâncias administrativas e jurisdicionais, com a condição de que haja um poder sobre todos, quer dizer, um poder supremo ao qual se reduzam e pelo qual se regulem os demais. Nederman afirma que Marsílio concorda com a pluralidade de níveis de poder, desde que estejam hierarquizados e subordinados a uma autori-

9 Cf. DP I, 17, 2: "Hunc autem solummodo principatum, supremum scilicet, dico unum numero ex necessitate fore, non plures, si debeat regnum aut civitas recte disponi. Idemque dico de principante secundum illum, non quidem unicum numero principantem secundum suppositum hamane speciei, sed secundum officium. Est enim principatus aliquis unicus numero supremus et bene temperatus, secundum quem principantur plures homines uno, ut aristocracia et policia. (...) Verum hii plures sunt unus principatus numero quantum ad officium, propter numeralem unitatem cuiuscumque accionis provenientis ab eis, iudicii seu sentencie vel precepti: nulla enim talium accionum provenire potest ab ipsorum aliquo seorsum, sed ex communi decreto atque consensu eorum aut valencioris partis secundum statutas leges in hiis. Et propter talem accionis numeralem unitatem sic provenientes ab eis est et dicitur principatus numero unus, sive unico regatur homine sive pluribus. Talis vero unitas accionum non requiritur in aliquo uno reliquorum officiorum seu parcium civitatis; possunt enim et debent in unoquoque ipsorum plures acciones consimiles aut diverse specie a diversis in eis suppositis provenire seorsum. Quinimo talis unitas accionis in eis esset communitati et singulis importabilis et nociva".

${ }^{10}$ Cf. Q. Skinner, The Foundations of Modern Political Thought, Cambridge, Cambridge University Press, Vol. II, 1978, p. 351. 
dade suprema ${ }^{11}$. A unidade de poder significa que somente existe um único governo ou governante na cidade ou reino, ou, se existem mais, o supremo de todos é somente um, não vários. Marsílio não defende a idéia de eliminação dos diferentes poderes, uma vez que considera esses como funções ou ofícios indispensáveis para a promoção da justiça e da paz. Considera-os como níveis de poder com certa autonomia funcional, mas é preciso que estejam subordinados a um governo superior. Nesse sentido, defende que o poder é um só.

Trata-se efetivamente de uma unidade de ordem, não de uma unidade absoluta, quer dizer, de muitos homens considerados um ou de um conjunto de pessoas que se afirma constituir algo único quantitativamente. Isto não significa, porém, que elas sejam uma pessoa formalmente, sob determinado aspecto, mas de fato o são, consideradas numericamente, visto assim serem denominadas em relação a uma unidade relativa ao número, isto é, o governo por quem são organizadas. O reino ou a cidade não é, pois, uma devido a alguma forma natural única, resultante da composição ou da mistura, uma vez que seus grupos sociais ou ofícios e os indivíduos que os integram ou ainda eles próprios são muitos em ato, e formalmente distintos entre si quanto ao número, estando igualmente separados uns dos outros no que concerne ao substrato e ao lugar [...] Daí a predicação, segundo a qual se afirma que todos os entes constituem um único mundo no que concerne ao número, não uma predicação formal de uma unidade numérica qualquer, presente em todos os seres, tampouco uma predicação de algum conceito universal relativo ao uno, trata-se, na verdade, de uma pluralidade de seres que se diz una porque existe em vista do uno e para o uno. Analogamente, se diz também que os habitantes de uma cidade ou província constituem uma cidade ou um reino, porque desejam um governo único quantitativamente..$^{12}$

11 Cf. Cary J. Nederman, Community and Consent: The Secular Political Theory of Marsiglio of Padua's Defensor pacis, Boston, Rowman \& Littlefield, 1995, p. 125: “The complexity of Marsiglio's arguments about the structure of jurisdiction becomes evident upon careful reading of Chapter 17 of Dictio I, where Marsiglio seeks to make two points: first, where it is necessary or preferable for a plurality of jurisdictions to be present, there must be some ordering among them; second, the most desirable jurisdictional configuration leaves one authority in principle supreme over the others in matters where conflict might arise. These two claims might form the basis for a case favoring the existence of a single government only in a community, and hence the suppression of all other jurisdictions".

12 Cf. DP I, 17, 11: "Ad propositam tamen nobis redeuntes intencionem, dicamus, ex hiis que dicta sunt aliqualiter apparere que sit numeralis unitas civitatis aut regni; quoniam hec unitas est ordinis, non simpliciter unitas, sed pluralitas aliquorum, que una dicitur: vel qui aliquid unum dicuntur numero, non propter hoc quod unum numero sint formaliter per aliquam formam, sed unum numero vere dicuntur propterea quod ad unum numero sunt et dicuntur, principatum scilicet, ad quem et propter quem ordinantur et gubernantur. Civitas enim aut regnum non est unorum per formam aliquam unicam naturalem, ut composicionis aut commixcionis, quoniam eius partes seu officia et harum parcium supposita sive partes sunt multa in actu et separata invicem numero formaliter, quoniam loco atque subiecto [...] Unde predicacio qua omnia encia dicuntur unus 
Gewirth assinala, não sem razão, a característica nominalista dessa definição de unidade ${ }^{13}$. Brocchieri afirma que, para esclarecer o conceito de unidade da comunidade política, Marsílio compara essa com o mundo, onde a unidade é definida aristotelicamente através da analogia dos entes. Todos os entes procedem de um primeiro e desse dependem, assim como o mundo depende metafisicamente de Deus, a comunidade política depende da vontade dos indivíduos, que se realiza por um governo único ${ }^{14}$.

Marsílio, após tratar da competência do governante civil, afirma o principio de sua exclusiva soberania. Lagarde considera que esse ponto é uma das chaves do sistema marsiliano; de todas as doutrinas contidas no mesmo, parece ser essa a que causará maior repercussão. A unidade não é natural, mas política, isto é, fundada sobre a vontade soberana da comunidade. A unidade originária é unidade legislativa ou de soberania e dela nasce a unidade do governo, sendo essa judicial e executiva. É essencial que, na civitas, haja uma só lei, um só juiz, uma só sentença ao final do processo e um só executor da sentença. O essencial é que o governante, seja na forma individual ou coletiva, possua unidade numérica na função, a saber, uma só lei, um único juiz, uma só sentença e a mesma execução das obras da justiça. Lagarde salienta essa condição importante com a qual Marsílio defende a soberania governamental ${ }^{15}$.

mundus numero, non est formaliter alicuius unitatis numeralis in eis omnibus, neque alicuius universalis dicti secundum unum, sed est pluralitas quorundam dicta unum, quia est ad unum et propter unum. Sic quoque unius civitatis aut provincie homines dicuntur una civitas aut regnum, quia volunt unum numero principatum."

13 Cf. Alan Gewirth, Marsilius of Padua, New York, Columbia University Press, Vol. I, 1951, p. 116: "Marsilius and the other Aristotelians take over this correction, declaring that a state is not one by composition, colligation, continuity, mixture, or natural form. Rather, the "nominalist" position is upheld that the state is a multitude of men who are one by a "unity of order," and this because they are ordered to and by one government".

14 Cf. Piero Di Vona, I principi del "Defensor pacis", Napoli, Morano, 1974, p.233: "Sono detti una città e uno Stato perchè vogliono un governo único di numero. Vi è però una differenza tra mondo e comunità política: nel primo caso infatti la pluralità degli enti è tale perché dipendono metafisicamente da Dio, nel secondo caso la pluralità degli uomini è resa 'una' dalla volontà degli individui che si danno un governo unico".

15 Cf. Georges de Lagarde, La Naissance de l'esprit Laique au Déclin du Moyen Âge, Louvain, Nauwelaerts, Vol. 3, 1970, p. 119-120: "Après avoir defini la compétence du gouvernement civil, Marsile affirme le principe de son exclusive souveraineté. C'est une dês clés de son système. De toutes lês doctrines, qu'il a professées, c'est celle qui renconterera le plus d'audience. Le titre du chapitre qui la définit parle du sens qu'il faut donner à l'unité du principat suprême dans la cite ou le royaume et de sa necessité. La démonstration, ajoute-t-on, nous fera comprendre ce qui fait l'unité numérique de la cité et du royaume, ainsi que celle de leurs principales parties. Quelles que soient ses préferences pour la monarchie, Marsile admet fort bien que ce pouvoir unique puisse être exercé par un collège plus ou moins large, comme c'est le cas dans l'aristocratie et la politie. L'essentiel est que le gouvernement individuel ou collectif soit unique: une seule loi (preceptum), um seul juge (judicium), une seule sentence au terme du procès (sententia), um seul exécuteur des oeuvres de justice (executio)". 
Bayona entende que, na filosofia política do paduano, o útil social estabelece o justo civil e implica a unidade de governo. Embora a civitas seja composta de diferentes partes, ela é uma, com uma só lei ou justiça e um só governo supremo. No caso de haver mais de um governo, se não existir um supremo, então a alternativa para a unidade é o caos e a guerra de todos contra todos. Percebemos, aqui, possíveis sementes das idéias hobbesianas ${ }^{16}$.

Afirma Marsílio:

Demonstraremos isso primeiramente alegando o seguinte: se houver muitos governantes na cidade ou no reino não estando subordinados ou sendo dirigidos pelo supremo mandatário, o julgamento e o preceito acerca do justo e a ação em proveito do bem comum serão deficitários. E então, como as injustiças praticadas pelos homens ficariam impunes, tal fato geraria inicialmente a luta, a divisão e finalmente a destruição da cidade ou do reino. Mas, essa conseqüência funesta proveniente da pluralidade inoportuna relativa a existência de muitos governantes é um dano tal à cidade que deve ser evitado a qualquer custo. ${ }^{17}$

O médico paduano entende que, se existem vários governos, não se pode fazer justiça. Algumas questões ficariam mal resolvidas. Diante de quem deve comparecer aquele que transgride a lei? Como vai alguém comparecer, ao mesmo tempo, diante de duas ou mais autoridades? Diante de quem deixa de comparecer e a quem desobedece? A quem deve pagar a multa? Ou deve pagar a todos? E o que acontece, caso alguém o condene e outro o absolva? Teria que fazer coisas contraditórias, ou não cumprir nenhuma pena. Portanto, conclui Marsílio, para manter o bem comum é impossível aceitar que haja na cidade ou no reino pluralidade de governos não subordinados entre si, como se cada um fosse soberano ou tivesse a sua própria fonte de legitimidade. Se houvesse diversos poderes autônomos, destruir-se-ia por completo a comum utilidade, que é o último fundamento da vida social, porque se obrigaria os mesmos cidadãos a reunirem-se em lugares distintos, convocados por diferentes

${ }_{16}$ Cf. Bernardo Bayona, Religión y poder. Marsilio de Padua: La primera teoria laica del Estado?, Madrid, Biblioteca Nueva, 2007, p. 172.

17 Cf. DP I, 17, 3: "Hoc autem sic primum monstrabimus: quoniam si principatus essent plures in civitate vel regno, et non reducti seu ordinati sub aliquo uno supremo, deficeret iudicium, preceptum et execucio conferencium et iustorum, et ex hiis propter invindicatas iniurias hominum pugna, separacio et corrupcio demum civitatis aut regni. Consequens autem istud est inconveniens maxime fugiendum, cuius quidem ad antecedens datum, pluralitatem scilicet principatuum, consequencia potest evidenter ostendi. Primum quidem, quoniam legum transgressores iustificari racionabiliter nequeunt, nisi vocati coram principante ad quesitorum seu ipsis obiectorum examinacionem". 
poderes para deliberar, e se tomariam, mais de uma vez, decisões sobre o mesmo ${ }^{18}$. Bayona salienta que a impossibilidade física é acompanhada pela contradição lógica, ou seja, repele aos princípios racionais admitir que possa haver mais de uma sentença justa de um mesmo litígio diante de vários tribunais. Nesse caso, os cidadãos sofreriam ameaças e perseguições, porque, dessa forma, seria impossível aos mesmos obedecer a poderes antagônicos ${ }^{19}$.

A falta de um supremo mandatário na cidade ocasionaria graves prejuízos à mesma, por exemplo: a divisão, o conflito, a oposição e a luta entre os cidadãos, pois enquanto um bom número deles obedeceria a um dos príncipes, outra parcela considerável dos mesmos poderia querer obedecer a um outro; os príncipes também entrariam em luta, pois um iria querer dominar o outro; os governantes igualmente lutariam contra os cidadãos, pois esses poderiam não querer mais obedecer a nenhum deles. Isso tudo acabaria finalmente na destruição da cidade. ${ }^{20}$

O filósofo de Pádua recorre ao princípio de economia e argumenta que é irracional buscar em mais de um governo o que se pode conseguir com um só ou com um supremo. A pluralidade de poderes é vã e supérflua, porque um único governo pode conseguir a utilidade civil melhor e sem os males que vários governos produziriam. Também nenhum reino pode subsistir com várias jurisdições. Existe comunidade política, se existe unidade de governo, para a qual e pela qual se ordenam todas as demais partes da cidade. Mas, se as partes não estão subordinadas a uma superior e não há ordem entre elas, reinará confusão na cidade, pois cada uma escolherá para si uma determinada função, conforme a sua vontade, sem uma ordem que as regule. Nesse caso, os inconvenientes seriam tantos, que não é fácil enumerá-los. A pluralidade de legitimidades é, portanto, contrária à razão de ser da sociedade, porque nenhuma cidade ou reino pode garantir a paz nessas condições, em que deixa de ser uma comunidade política.

Contudo, deve-se ressaltar que Marsílio não requer tal unidade de atuação dentro das demais partes da cidade. Ao contrário, chega a dizer que tal unidade de atuação seria intolerável e nociva para a comunidade

18 Cf. $D P$ I, 17, 3.

19 Cf. B. Bayona, El origen del estado laico desde la Edad Media, Madrid, Tecnos, 2009, p. 245.

20 Cf. DP I, 17, 5: "Rursum contingeret ex hoc civium seccio et opposicio, pugna et separacio, demumque civitatis corrupcio, volentibus quibusdam ipsorum uni principatuum obedire, quibusdam vero alteri; inter principatus quoque invicem, propter velle supergredi quemcumque ipsorum ad alterum; adhuc principatuum ad cives sibi recusantes subesse. Et amplius principatibus dissidentibus aut invicem contendentibus et iudice superiori carentibus, orirentur scandala supradicta". 
e para os indivíduos particulares. Não porque lhe importe o pluralismo interno de cada uma das corporações, mas, teme que, se alguma for muito compacta, considerar-se-á forte diante do governo legítimo. Se as diferentes partes cidadãs pudessem exigir de seus membros o mesmo grau de obediência que o governo, surgiriam a confrontação e os escândalos, pois não é possível que haja a paz, onde vários dirigentes rivalizam entre si para conseguir a obediência dos cidadãos. Esses, por obedecerem a um ou a outro, desencantam-se, dividem-se e lutam. Portanto, a unidade referida com as partes não significa a unidade intrínseca delas, mas a subordinação de todas ao único poder civil, isto é, ao governo, ao qual e pelo qual se ordenam. As partes da cidade não são unitárias como é o reino e, se delas também se predica a unidade, não obstante o grande número de pessoas que existem nas mesmas, não é porque tenham em si, de forma inerente, algo em comum, mas porque estão referidas a um único encargo ativo do que governa, segundo a determinação da lei. A unidade que liga as partes é a unidade do Estado e do governo que as estabeleceu e ao qual têm de submeter-se.

Os grupos sociais que desempenham diferentes funções não são entidades com autonomia, mas que estão a serviço da lei comum. A pluralidade de unidades autônomas significaria pluralidade de príncipes e furtaria ao governo a sua competência para designar e controlar os cargos. É o que acontece, quando o clero se imiscui nas nomeações de cargos civis ou eclesiásticos e aplica uma jurisdição eclesiástica independente do poder temporal. Em harmonia com a unidade de governo, só a esse, com a autoridade do legislador humano, entendido como a universitas civium ou a sua valencior pars, compete castigar as pessoas e os grupos. Nenhuma outra parte da cidade tem legitimidade para fazê-lo. Não é competência dos sacerdotes e bispos julgar e castigar os hereges, cismáticos ou qualquer outro tipo de infiéis, por mais que tenham pecado contra a lei divina. Essa tarefa compete só ao governante. Marsílio conclui o capítulo 17 do Defensor Pacis não deixando dúvida a respeito da inconveniente intromissão dos clérigos no governo da comunidade política. O poder dos sacerdotes nada mais é que um ofício ou uma função de educar na fé e administrar os sacramentos ${ }^{21}$.

${ }^{21}$ Cf. Jeannine Quillet, Introdução e notas. In: Marsile de Padoue, Le Défenseur de la paix, Paris, Vrin, 1968, p. 163: "Cette conclusion est dirigée, sans aucun doute, contre toute tentative d'ingérence des clercs et de la paupaté dans les affaires temporelles. L'autorité politique est unique et indivisible: comme telle, elle est le meilleur garant de la paix. On voit que ce chapitre, theorique en apparence, est en réalité profondément polémique. C'est en s'appuyant sur ces démonstations que Marsile va battre en brèche, dans la Seconde Dictio, le sophisme de la plenitude de puissance pontificale et les abus qui en ont résultés. Le Defensor Minor insistera également sur la nécessité de l'unité et de l'unicité du gouvernement". 
Neste sentido, Marsílio propõe que sejam abolidos os tribunais eclesiásticos:

Nenhum indivíduo singularmente considerado, pouco importa sua dignidade ou estado, tampouco qualquer grupo social, tem competência para exercer o governo ou uma jurisdição coerciva sobre quem quer que seja aqui neste mundo, a menos que a autoridade para tanto lhe tenha sido conferida imediatamente pelo legislador humano ou pelo Legislador Divino. ${ }^{22}$

O opúsculo do filósofo de Pádua é profundamente polêmico, pois se contrapõe a outra doutrina. O seu propósito é não deixar resquício algum para a aparição de outro poder ou outra jurisdição autônoma, porque não há outra frente de legitimidade, nem outra sociedade paralela à comunidade política. Não há dois tipos de cidadania: civil e cristã. Também não há cidadãos isentos da jurisdição ordinária, e ninguém que não seja o governo, ainda que seja o Bispo de Roma, tem pleno poder sobre os cidadãos cristãos. Não existe poder sacerdotal, senão que o poder civil é o único e pleno poder. O princípio filosófico da unidade do poder é o caráter único e indivisível da universitas civium e expressa-se na unidade de governo, em todas as competências ou manifestações do poder. Marsílio, no Defensor Minor, refuta a duplicidade do poder e impugna a doutrina de uma autoridade sacerdotal distinta, em virtude da lei divina, que, além de supérflua, seria desfavorável e prejudicial.

Respondemos afirmando que tais aspectos estão amplamente estatuídos e ordenados pelas leis divina e humana coercivas, quer para a vida presente, quer para a futura. Daí, tudo que os sacerdotes, ou exclusivamente sua corporação, estabelecerem quanto a esses assuntos será totalmente inútil. É por isso também que se deve simplesmente negar que a premissa menor relativa ao que foi dito, pois tal seria desnecessário e sem finalidade e só geraria inconvenientes. ${ }^{23}$

22 Cf. DP I, 17, 13: "Concludi potest evidenti demonstracione, nulli persone singulari, cuiuscumque dignitatis aut status existat, neque collegio cuipiam convenire principatum seu iurisdiccionem aliquam cuiusquam in hoc seculo coactivam, nisi per legislatorem divinum aut humanum immediate sibi tradita fueri auctoritas ista".

23 Cf. Marsílio de Pádua. Defensor Minor. Paris, Centre National de la Recherche Scientifique, 1979, livro II, capítulo 3: "Nos autem dicamus, quod per legem divinam et humanam coactivas iam dictas haec sufficienter ordinata sunt et statuta, tam pro statu praesentis saeculi quam venturi. Unde de huiusmodi quidquam per sacerdotes aut ipsorum solum collegium statutum esset totaliter otiosum; propter quod et minor similiter praefati simpliciter est neganda, et esset inexpediens et inutile, propter inconvenientia, quae sequuntur ad hoc". 
O paduano reitera que tal autoridade não seria humana (só o é a universitas civium ou a quem essa delegue), nem divina (só Deus o é). E dessa suposta autoridade derivariam outros inconvenientes, com o que haveria vários legisladores em uma mesma comunidade e, portanto, vários responsáveis de castigar ao mesmo povo, nenhum dos quais querendo subordinar-se ao outro. Isso causaria a dissensão perpétua entre os cristãos e produziria uma divisão insuportável para qualquer comunidade. O último inconveniente, não menos grave, é que se os sacerdotes fossem legisladores humanos seriam supérfluas as leis dos cidadãos e dos governantes.

Damiata recorda que as diversas partes da civitas se estabelecem como uma articulação da vida social na variedade do seu ser e do seu agir, onde não se pode compreender que os membros de um mesmo organismo estejam separados. Para evitar tal perigo, Marsílio empenhou-se na luta contra a plenitudo potestatis, a qual, entre outras causas que ameaçam a unidade do governo, vem retalhar o corpo dos cidadãos, uma vez que coloca o clero como uma entidade com legislação própria ${ }^{24}$. Damiata salienta, ainda, que o argumento em favor da unidade é algo natural e utilizado por todos, inclusive pelos defensores da teocracia ${ }^{25}$.

Concluindo, só há um poder. O nosso autor recorre à idéia de que Deus é a causa do poder no mundo: "todo poder vem de Deus" (Rm 13.1). Mas, Deus é causa remota e mediata, pois a causa imediata da ordem política é o povo ou a vontade dos cidadãos. Nas comunidades não cristãs, devese obedecer ao príncipe, pois ainda que seja infiel, é imago Dei, segundo a doutrina paulina, e aqueles que resistem ao poder civil constituído se condenam $^{26}$. Quillet esclarece que Marsílio explora, detalhadamente, as epístolas paulinas para demonstrar que a missão do príncipe é divina. Nesse sentido, afirma a exclusividade, a unidade e a infalibilidade do poder secular no que diz respeito ao uso do poder coercivo, inclusive sobre o clero, pois toda alma deve estar submissa ao governante ${ }^{27}$.

${ }^{24}$ Cf. Marino Damiata, Plenitudo potestatis e universitas civium in Marsilio da Padova, Firenze, Studi Francescani, 1983, p. 200.

25 Id. ibid., p. 204-205: "Senza l'unità, si andrebbe per così dire contro natura, la quale - come a tutti è possibile constatare - se ha dotato um organismo di più membra, lo ha fornito sempre di un solo capo o principio motore, scrive Marsilio appropriandosi di un argomento tipico dei teocratici per rivendicare un'autorità suprema ed illimitata al sommo pontefice. Per concludere, senza unità si ucciderebbe - se così è lecito esprimersi - la civitas, la quale in tanto sussiste, in quanto riesce a conservare la sua compatezza".

${ }^{26}$ Cf. DP II, 5,5 e 26,13.

27 Cf. J. Quillet, La Philosophiae Politique de Marsile de Padoue, Paris, Vrin, 1970, p. 111: "Le pouvoir dont est investi le Prince en ce monde est sanctionné par Dieu lui-même. Par une série de citations scripturaires vont être réunies dês preuves de caractere 
Quillet lembra que, para Marsílio, religião e política são inseparáveis. Nesse sentido, o nosso autor se caracteriza como um pensador medieval, ainda que na sua tematização em favor de um poder laico, porém não antirreligioso, venha caracterizá-lo como um teórico moderno ${ }^{28}$. $\mathrm{Na}$ cristandade, a identidade entre universitas civium e universitas fidelium faz que a Igreja coincida com as estruturas políticas e proporcione uma posição de convergência entre as duas ordens, ou seja, o reino e o sacerdócio. Afirmar que existe um poder religioso distinto do poder temporal é desconhecer a ordem querida por Deus. O caráter unitário do poder e a sua remissão última à origem divina permitem a Marsílio unificar o poder temporal e eclesiástico, até mesmo ver no imperador um ministro de Deus ${ }^{29}$. Existe apenas um poder civil, e esse é humano.

théologique, montrant que le prince ne dépend que de Dieu pour tout ce qui concerne son autorité et que, par conséquent, elle ne peut être contestée ou remise en cause par aucune institution. Mais la démonstration de l'origine divine de l'autorité divine de l'autorité temporelle est en quelque sorte négative (...) Si le Christ Lui-même s'est soumis à la sentence de Pilate, vicaire de César, c'est parce que le pouvoir de César vient d'en haut, ce que souligne également sain Paul: Il n'est de pouvoir - c'est-à-dire, ajoute Marsile, d'autorité de juridiction - que de Dieu, quoi qu'il en soit du mauvais usage qu'on en fasse, commente Saint Augustin cite dans ce passage. Les épitres pauliniennes constituent, dans cette démonstration de l'exclusivité, de l'unité et de l'infaillibilité du pouvoir du prince le centre de l'argumentation: Que toute â me soit soumise aux pouvoirs supérieurs, c'est-à-dire, pour Marsile, aux pouvoirs séculiers."

28 Cf. J. Quillet, La Philosophiae Politique de Marsile de Padoue, Paris, Vrin, 1970, p. 105-106: "C'est que politique et religion sont inseparábles, mieux, elles se confondent presque puisqu'on ne peut établir de clivage, dans cet ouvrage, entre valeurs séculières et les valeurs religieuses".

${ }^{29}$ Cf. DP I, 1, 6: “... erguendo meu semblante para ti, mui ilustre Luís, Imperador dos Romanos, que na condição particular de ministro de Deus...". 